\title{
Isolamento e regeneração de protoplastos de Magnaporthe grisea
}

\author{
Carlos Eduardo Marchi ${ }^{1}$, Sérgio Hermínio Brommonschenkel ${ }^{1}$, Marisa Vieira de Queiroz ${ }^{2}$, \\ Eduardo Seiti Gomide Mizubuti ${ }^{1}$
}

1Depto. de Fitopatologia, ²Depto. de Microbiologia, UFV, CEP 36570-000, Viçosa-MG. e-mail: cemarchi@cnpgc.embrapa.br, shbromo@ufv.br, mizubuti@ufv.br, mvqueiro@ufv.br

Parte da Tese do $1^{\circ}$ autor.

Data de chegada: 13/12/2004. Aceito para publicação: 04/11/2005.

\section{ABSTRACT}

Marchi, C.E., Brommonschenkel, S.H., Queiroz, M.V. de, Mizubuti, E.S.G. Isolation and regeneration of Magnaporthe grisea protoplasts. Summa Phytopathologica, v.32, n.3, p.232-238, 2006.

Protoplasts are important biological tools in filamentous fungi research. Fungal protoplasts have been extensively used in experiments with genetic transformation. Protoplastization of Magnaporthe grisea was accomplished with Novozym 234, however, this enzymatic complex is no commercially available for purchase. Thus, the efficiency of several other commercial enzymes in $M$. grisea protoplasts preparation was investigated. At the same time, osmotic buffer, digestion time and regeneration rate were also analyzed. The highest protoplasts producti- on was obtained with Lysing Enzymes plus Cellulase Onozuka R-10. The use of 10 or $15 \mathrm{mg}$ of each enzymatic complex in $3 \mathrm{~mL}$ of osmotic buffer was most effective for the protoplasts yields. The best osmotic buffer was $\mathrm{MgSO}_{4} 1.2 \mathrm{M} / \mathrm{NaH}_{2} \mathrm{PO}_{4} 0.01 \mathrm{M}, \mathrm{pH} 5.8$, followed by $\mathrm{MgSO}_{4} 0.8 \mathrm{M} / \mathrm{NaH}_{2} \mathrm{PO}_{4} 0.01 \mathrm{M}, \mathrm{pH}$ 5.8. The M. grisea protoplasts yield, evaluated at each $60 \mathrm{~min}$, increased with 3 to 6 hours of incubation. However, the highest regeneration frequency (19.4\%) was recorded for protoplasts obtained with 3 hours of enzymatic hydrolyse.

Additional key words: Protoplastization, rice blast, Pyricularia grisea.

\section{RESUMO}

Marchi, C.E., Brommonschenkel, S.H., Queiroz, M.V. de, Mizubuti, E.S.G. Isolamento e regeneração de protoplastos de Magnaporthe grisea. Summa Phytopathologica, v.32, n.3, p.232-238, 2006.

Protoplastos são ferramentas biológicas importantes para pesquisas em fungos filamentosos, sendo empregados intensamente em transformação genética. O isolamento de protoplastos de Magnaporthe grisea foi facilitado com Novozym 234, contudo, este complexo enzimático encontra-se indisponível no mercado. Assim, objetivou-se comparar a eficiência de enzimas líticas disponíveis comercialmente na obtenção de protoplastos de $M$. grisea. Paralelamente, analisaram-se estabilizadores osmóticos, tempos de digestão e freqüência de regeneração. Maior produção de protoplastos foi obtida com o uso simultâneo de Lysing Enzymes e Cellulase Onozuka R-10. O uso de 10 ou $15 \mathrm{mg}$ de cada complexo enzimático, em $3 \mathrm{~mL}$ de estabilizador osmótico, resultou em maior liberação de protoplastos. O melhor estabilizador osmótico foi $\mathrm{MgSO}_{4} 1,2 \mathrm{M} / \mathrm{NaH}_{2} \mathrm{PO}_{4}$ $0,01 \mathrm{M}, \mathrm{pH} 5,8$, seguido por $\mathrm{MgSO}_{4} 0,8 \mathrm{M} / \mathrm{NaH}_{2} \mathrm{PO}_{4} 0,01 \mathrm{M}, \mathrm{pH}$ 5,8 . O isolamento de protoplastos foi monitorado a cada $60 \mathrm{minu}-$ tos, atingindo o máximo após incubação por 3 a 6 horas. No entanto, maior freqüência de regeneração $(19,4 \%)$ foi registrada para protoplastos obtidos após 3 horas de hidrólise enzimática.

Protoplastização, brusone, Pyricularia grisea.

A protoplastização é procedimento bem estabelecido para fungos filamentosos (18). Os protoplastos, células artificialmente desprovidas de parede, foram inicialmente explorados em estudos morfológicos, bioquímicos e fisiológicos, e recentemente têm constituído ferramentas biológicas importantes para a manipulação genética de fungos filamentosos. Eles são requeridos para a fusão somática de indivíduos pertencentes a gêneros ou espécies distintas, para a determinação do número e/ou tamanho de cromossomos e para a localização de genes específicos em cromossomos por meio de PFGE, eletroforese de campo pulsado
(18). Além disso, os protoplastos são substratos importantes para a técnica REMI (Restriction Enzyme-Mediated Integration), e outros métodos de transformação genética (22).

Em geral, os protoplastos são obtidos a partir de micélio jovem ou esporos assexuais, germinados ou não; algumas vezes, basidiósporos podem ser usados, como no caso de Agaricus $(7,21)$. Usualmente, a remoção da parede celular ocorre pela ação de enzimas líticas, em meio osmoticamente balanceado. Além da espécie fúngica e do tipo de célula utilizada, a liberação de protoplastos depende de fatores como: (a) a 
composição do meio de cultivo; (b) o estado fisiológico da cultura; (c) o tipo e a concentração da enzima lítica; (d) o tipo e a concentração do estabilizador osmótico; (e) o tempo de digestão, e (f) o pH e a temperatura do sistema. Após o isolamento, quando em meio nutritivo apropriado, os protoplastos são capazes de regenerar a parede celular, dando origem ao micélio. Contudo, as taxas de regeneração e reversão variam de organismo para organismo, geralmente não atingindo $100 \%(1)$.

Protoplastos de Magnaporthe grisea (Hebert) Barr. (anamorfo: Pyricularia grisea Sacc.), principal patógeno da cultura do arroz (16), foram originalmente obtidos com o uso de combinação de enzimas comerciais (10). Complexo enzimático extraído de Bacillus circulans também foi relatado como capaz de protoplastizar o ascomiceto (27). Contudo, a produção de enzimas a partir de microrganismos é trabalhosa e as preparações têm variações na proporção relativa das diferentes enzimas líticas.

A protoplastização de $M$. grisea foi facilitada com Novozym 234 (Novo Nordisk Ltd.), devido à sensibilidade da parede celular a este complexo hidrolítico à base de glucanases e quitinases, extraído de Trichoderma sp. Novozym 234 tornou-se o sistema enzimático praticamente universal para a obtenção de protoplastos de M. grisea $(4,24,25,26)$. No entanto, atualmente Novozym 234 não se encontra disponível no mercado.

A indisponibilidade de Novozym 234 e a necessidade de obter protoplastos para o emprego de mutagênese insercional mediada por REMI, motivaram a avaliação da eficiência de enzimas líticas, disponíveis comercialmente, na protoplastização de M. grisea. Estudaram-se também o tipo e a concentração de estabilizadores osmóticos, tempos de digestão e a regeneração dos protoplastos.

\section{MATERIALEMÉTODOS}

\section{Magnaporthe grisea e condições de cultivo}

Foram utilizados os isolados I-21 e I-22, patogênicos ao arroz, gentilmente cedidos pelo Laboratório de Fitopatologia Molecular da UFRGS, Porto Alegre, RS. O cultivo foi feito em meio de farinha de arroz-ágar (FAA - $20 \mathrm{~g}$ de farinha de arroz com casca; $5 \mathrm{~g}$ de sacarose; $15 \mathrm{~g}$ de ágar; $1 \mathrm{~L}$ de água destilada) por 5-7 dias a $28^{\circ} \mathrm{C}$, no escuro. Para a preservação dos isolados, segmentos $\left(4 \mathrm{~cm}^{2}\right)$ de papel-manteiga colonizados pelo micélio foram mantidos a $80^{\circ} \mathrm{C}(29)$.

Para isolar os protoplastos, inicialmente obteve-se culturaestoque dos isolados. Discos de ágar com micélio do fungo foram transferidos para erlenmeyer $250 \mathrm{~mL}$ contendo meio completo (MC - sacarose 0,5\%; extrato de levedura 0,6\%; caseína ácida hidrolisada $0,6 \%$ ) e incubados sob agitação (130-150 rpm) a 28$30^{\circ} \mathrm{C}$, por 4 dias. Fração da cultura-estoque foi transferida para outro erlenmeyer $250 \mathrm{~mL}$ contendo MC e permitida crescer por 48 $\mathrm{h}$ nas mesmas condições.

\section{Obtenção dos protoplastos de $M$. grisea}

Após 48 h de cultivo, o micélio foi filtrado, lavado duas vezes com estabilizador osmótico e secado em câmara de fluxo, por alguns minutos. $\mathrm{O}$ procedimento padrão para a protoplastização foi a adição da enzima lítica em $3 \mathrm{~mL}$ de estabilizador osmótico contendo $100 \mathrm{mg}$ de micélio úmido. Esta mistura foi incubada sob agitação $(100 \mathrm{rpm})$ a $28-30^{\circ} \mathrm{C}$, por período de $1-6 \mathrm{~h}$.

Todos os fatores foram analisados em dois ensaios independentes, e cada tratamento foi aplicado em quatro unidades experimentais (erlenmeyer $25 \mathrm{~mL}$ ). Os protoplastos foram observados ao microscópio e quantificados em câmara de Neubauer.

\section{Digestão do micélio}

Foram testados os sistemas líticos: 1 - Controle (sem enzima lítica); 2 - Lyticase (Sigma Chemicals Co.); 3 - Lysing Enzymes (Sigma Chemicals Co.); 4 - Driselase (Sigma Chemicals Co.); 5 Glucanex (Novo Nordisk Ltd.); 6 - Cellulase Onozuka R-10 (Yakult Biochemical Co. Ltd.); 7 - Lysing Enzymes + Cellulase Onozuka R10; 8 - Glucanex + Cellulase Onozuka R10 e 9 - Lysing Enzymes + Glucanex. Quinze miligramas de enzima foram misturados ao estabilizador osmótico $\mathrm{MgSO}_{4} 1,2 \mathrm{M} / \mathrm{NaH}_{2} \mathrm{PO}_{4}$ $0,01 \mathrm{M}, \mathrm{pH} 5,8$. Quando em combinações, as enzimas foram usadas em proporções iguais (7,5 mg de cada enzima). A protoplastização foi realizada por $5 \mathrm{~h}$.

\section{Concentração da enzima lítica}

Para estabelecer a melhor relação massa micelial:enzima, seguindo os mesmos procedimentos, foram preparadas misturas para a digestão com diferentes quantidades $(\mathrm{mg})$ do sistema enzimático que liberou o maior número de protoplastos. A protoplastização foi realizada por $5 \mathrm{~h}$, na presença do estabilizador osmótico $\mathrm{MgSO}_{4} 1,2 \mathrm{M} / \mathrm{NaH}_{2} \mathrm{PO}_{4} 0,01 \mathrm{M}, \mathrm{pH} 5,8$.

\section{Tipos de estabilizadores osmóticos}

Verificou-se a eficiência de estabilizadores osmóticos usados comumente na protoplastização de fungos filamentosos, os quais incluíram: 1 - Controle (água destilada); $2-\mathrm{MgSO}_{4} 0,6 \mathrm{M} / \mathrm{NaH}_{2} \mathrm{PO}_{4}$ $0,01 \mathrm{M}, \mathrm{pH} 5,8 ; 3-\mathrm{MgSO}_{4} 0,8 \mathrm{M} / \mathrm{NaH}_{2} \mathrm{PO}_{4} 0,01 \mathrm{M}, \mathrm{pH} 5,8 ; 4$ $\mathrm{MgSO}_{4} 1,2 \mathrm{M} / \mathrm{NaH}_{2} \mathrm{PO}_{4} 0,01 \mathrm{M}, \mathrm{pH} 5,8 ; 5-\mathrm{KCl} 0,7 \mathrm{M} / \mathrm{NaH}_{2} \mathrm{PO}_{4}$ $0,1 \mathrm{M}, \mathrm{pH} 5,9 ; 6-\mathrm{NaCl}_{4}, 8 \mathrm{M} / \mathrm{NaH}_{2} \mathrm{PO}_{4} 0,1 \mathrm{M}, \mathrm{pH} 5,8 ; 7$ - Sorbitol $0,6 \mathrm{M} / \mathrm{Na}_{2} \mathrm{HPO}_{4} 0,1 \mathrm{M}, \mathrm{pH} 8,0$ e 8 - Sacarose 20\% / EDTA $50 \mathrm{mM}$ / citrato tri-sódico $20 \mathrm{mM}, \mathrm{pH} \mathrm{8,0.} \mathrm{O} \mathrm{processo} \mathrm{de} \mathrm{isolamento} \mathrm{de}$ protoplastos foi realizado por $5 \mathrm{~h}$, utilizando-se o binômio sistema enzimático:concentração mais eficiente.

\section{Tempos de exposição ao sistema enzimático}

Detectada a combinação sistema enzimático:concentração: estabilizador osmótico mais eficiente, monitorou-se a protoplastização em função do tempo de incubação (1-6 h). A cada hora, frações da suspensão de protoplastos foram retiradas assepticamente de cada repetição, com pipeta, e quantificadas em câmara de Neubauer.

\section{Regeneração dos protoplastos de M. grisea}

Após adequar as condições para a protoplastização, suspensões purificadas de protoplastos, obtidas com 3,4 ou $5 \mathrm{~h}$ de hidrólise enzimática, foram examinadas quanto à capacidade de regeneração da parede celular.

Sistema de duas fases líquidas foi usado para purificar os protoplastos. Os protoplastos liberados em $\mathrm{MgSO}_{4} 1,2 \mathrm{M} /$ $\mathrm{NaH}_{2} \mathrm{PO}_{4} 0,01 \mathrm{M}, \mathrm{pH} 5,8$ foram colocados em tubo corex $(15 \mathrm{~mL})$ e, suavemente, adicionaram-se $4 \mathrm{~mL}$ de estabilizador ST (sorbitol $0,6 \mathrm{M}$, Tris- $\mathrm{HCl} 0,1 \mathrm{M}, \mathrm{pH} 8,0)$. Seguida centrifugação em rotor de caçamba (3000 rpm/5 min), os protoplastos se agregaram na interface dos estabilizadores. Os protoplastos foram recolhidos, transferidos para outro tubo corex, ressuspendidos em $2 \mathrm{~mL}$ de estabilizador STC (sorbitol $1 \mathrm{M}$, Tris- $\mathrm{HCl} 0,05 \mathrm{M}, \mathrm{CaCl}_{2} 0,05 \mathrm{M}$, $\mathrm{pH} 8,0)$ e precipitados por centrifugação (5000 rpm/10 min). Após 
três ciclos de lavagem em STC, ajustou-se a concentração da suspensão de protoplastos para $10^{7} / \mathrm{mL}$ em STC.

Preliminarmente, a regeneração dos protoplastos I-22, liberados com 5 h de incubação, foi avaliada em cinco meios de regeneração: TB3 (sacarose 20\%; extrato de levedura 0,3\%; caseína ácida hidrolisada 0,3\%; ágar 2\%); BDA acrescido de $\mathrm{MgSO}_{4}$ 1,2 M, pH 5,8; BDA acrescido de $\mathrm{NaCl} 0,8 \mathrm{M}, \mathrm{pH} 5,8$; BDA acrescido de sorbitol $1 \mathrm{M}, \mathrm{pH}$ 8,0 e Czapek contendo sacarose $20 \%$ e ágar $2 \%$. Embora não quantificada, a freqüência de regeneração foi aparentemente maior em TB3. Assim, TB3 foi selecionado para avaliar o efeito do tempo de digestão na capacidade regenerativa dos protoplastos, o qual foi avaliado em dois ensaios.

Frações da suspensão de protoplastos $\left(10^{7} / \mathrm{mL}\right)$ foram plaqueadas em placas de Petri pela técnica do cultivo em mistura (pour plate), usando-se TB3 ou meio completo-ágar (MCA sacarose $0,5 \%$; extrato de levedura $0,3 \%$; caseína ácida hidrolisada $0,3 \%$; ágar 2\%). Foram utilizadas 12 repetições (placas de Petri), as quais foram mantidas a $28^{\circ} \mathrm{C}$, na ausência de luz, por 7 dias. Calculou-se a regeneração segundo a fórmula: Regeneração (\%) $=(\mathrm{A}-\mathrm{B}) / \mathrm{C}$ x 100, onde $\mathrm{A}-\mathrm{n}^{\circ}$ de colônias desenvolvidas em TB3, $\mathrm{B}-\mathrm{n}^{\circ}$ de colônias desenvolvidas em MCA e C - $\mathrm{n}^{\circ}$ total de protoplastos plaqueados.

Avaliou-se a freqüência de colônias abortadas, inaptas a reverter para a forma micelial. Para isso, transferiram-se seis colônias das placas de regeneração de cada tratamento para placas de Petri contendo FAA. Dez placas por tratamento foram preparadas e incubadas a $28^{\circ} \mathrm{C}$, na ausência de luz.

\section{RESULTADOS}

\section{Obtenção dos protoplastos de M. grisea \\ 1. Digestão do micélio}

A protoplastização de $M$. grisea I-21 foi influenciada pelo sistema enzimático. Nos dois ensaios, houve a mesma tendência para a eficiência dos tratamentos, não se observando protoplastos quando Driselase ou Lyticase foi utilizada (Figura 1). O micélio I21 foi sensível a Lysing Enzymes ou a Glucanex. A combinação de Lysing Enzymes e Cellulase Onozuka R10 aumentou a liberação de protoplastos em $225 \%$ e $59 \%$ no primeiro e no segundo ensaio, respectivamente, quando comparada com Lysing Enzymes isolada. Do mesmo modo, a combinação de Glucanex e Cellulase Onozuka R10 foi mais eficiente do que Glucanex (Figura 1). Agindo individualmente, Cellulase Onozuka R10 liberou protoplastos apenas no segundo ensaio.

M. grisea I-22 foi submetido à protoplastização, e novamente, Driselase ou Lyticase não promoveu a liberação de protoplastos (Figura 2). A produção de protoplastos obtida com Cellulase Onozuka R10 no primeiro e no segundo ensaio foi de 4,4 e 5,0 x $10^{5} / \mathrm{mL}$, respectivamente. Lysing Enzymes e Glucanex, separadamente, promoveram liberação eficiente de protoplastos, com médias superiores a $10^{7}$ protoplastos $/ \mathrm{mL}$. Porém, I-22 foi mais sensível à combinação de Lysing Enzymes e Cellulase Onozuka R10, seguida pela combinação de Glucanex e Cellulase Onozuka R10.

\section{Concentração da enzima lítica}

Produção de protoplastos satisfatória foi obtida com o uso Lysing Enzymes + Cellulase Onozuka R10. Assim, o efeito da concentração enzimática no isolamento de protoplastos de $M$.

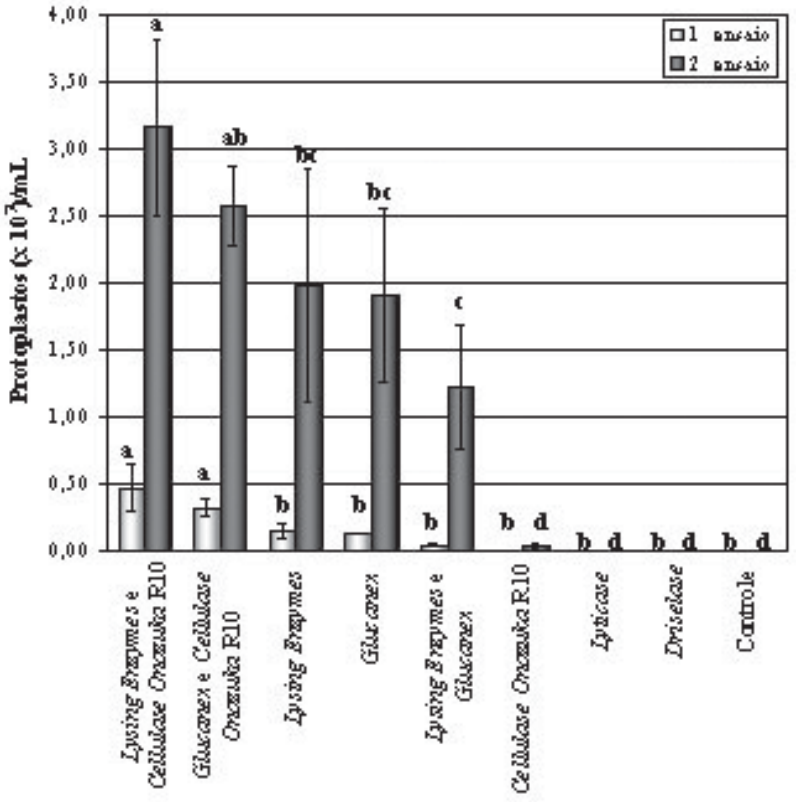

Sistema enximátice

Figura 1. Número de protoplastos de Magnaporthe grisea, isolado I21 , após $5 \mathrm{~h}$ de incubação $\left(28-30^{\circ} \mathrm{C} ; 100 \mathrm{rpm}\right)$ em diferentes sistemas enzimáticos. Mistura de digestão: $100 \mathrm{mg}$ de micélio, $15 \mathrm{mg}$ de enzima e $3 \mathrm{~mL}$ de $\mathrm{MgSO}_{4} 1,2 \mathrm{M} / \mathrm{NaH}_{2} \mathrm{PO}_{4} 0,01 \mathrm{M}, \mathrm{pH} 5,8$. Quando em combinação, foram utilizadas $7,5 \mathrm{mg}$ de cada enzima. As barras representam o desvio padrão. Em cada ensaio, tratamentos com mesma letra não diferem entre si pelo teste de Tukey $5 \%$.

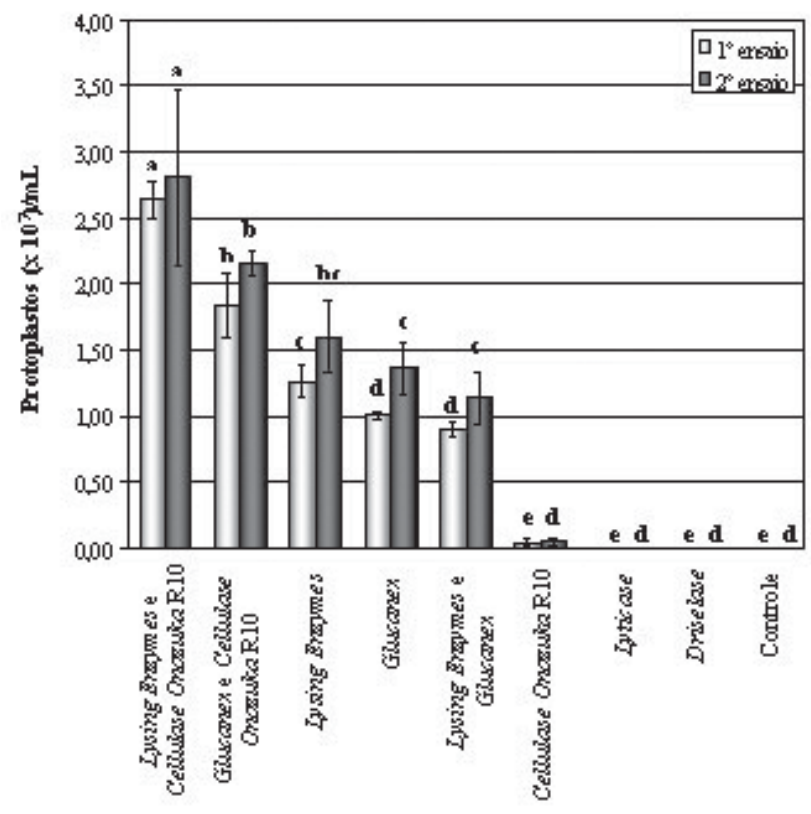

Sistema enximátic o

FIGURA 2. Número de protoplastos de Magnaporthe grisea, isolado $\mathrm{I}-22$, após $5 \mathrm{~h}$ de incubação $\left(28-30^{\circ} \mathrm{C} ; 100 \mathrm{rpm}\right)$ em diferentes sistemas enzimáticos. Mistura de digestão: $100 \mathrm{mg}$ de micélio, $15 \mathrm{mg}$ de enzima e $3 \mathrm{~mL}$ de $\mathrm{MgSO}_{4} 1,2 \mathrm{M} / \mathrm{NaH}_{2} \mathrm{PO}_{4} 0,01 \mathrm{M}, \mathrm{pH}$ 5,8. Quando em combinação, foram utilizadas $7,5 \mathrm{mg}$ de cada enzima. As barras representam o desvio padrão. Em cada ensaio, tratamentos com mesma letra não diferem entre si pelo teste de Tukey $5 \%$. 
grisea foi avaliado com base nessa combinação de enzimas (Figura 3 ). Este ensaio e os posteriores foram conduzidos apenas com o isolado I-22. As concentrações testadas variaram de 2,5 a $15 \mathrm{mg}$ de cada enzima em $3 \mathrm{~mL}$ de estabilizador osmótico.

No geral, constatou-se incremento na produção de protoplastos com o aumento da concentração enzimática (Figura 3). Em ambos os ensaios, maior número de protoplastos foi alcançado quando cada enzima foi usada em quantidade superior a $\quad 7,5 \mathrm{mg}$. A concentração de protoplastos atingiu o máximo utilizando-se $10 \mathrm{mg}$ de Lysing Enzymes e $10 \mathrm{mg}$ de Cellulase Onozuka R10, sendo a média dos ensaios de 4,9 x $10^{7}$ protoplastos $/ \mathrm{mL}$. Esta foi reduzida para $4,6 \times 10^{7}$ protoplastos $/ \mathrm{mL}$ quando se utilizou o sistema lítico mais concentrado, ou seja, 15 mg de cada enzima (Figura 3 ).

\section{Tipos de estabilizadores osmóticos}

A protoplastização foi influenciada pelo estabilizador osmótico utilizado (Figura 4). Nos dois ensaios houve a mesma tendência para a eficiência dos estabilizadores osmóticos. Maior liberação de protoplastos foi constatada com a solução $\mathrm{MgSO}_{4}$ $1,2 \mathrm{M}$, com médias de 5,1 e 5,0 $\times 10^{7}$ protoplastos $/ \mathrm{mL}$ no primeiro e no segundo ensaio, respectivamente (Figura 4). A solução de $\mathrm{MgSO}_{4}$ 0,8 M também foi eficiente no isolamento de protoplastos, com média dos ensaios de $4,1 \times 10^{7}$ protoplastos $/ \mathrm{mL}$. A estabilização com $\mathrm{MgSO}_{4} 0,6 \mathrm{M}$ foi similar à obtida com $\mathrm{KCl}$ 0,7 M(Figura 4).

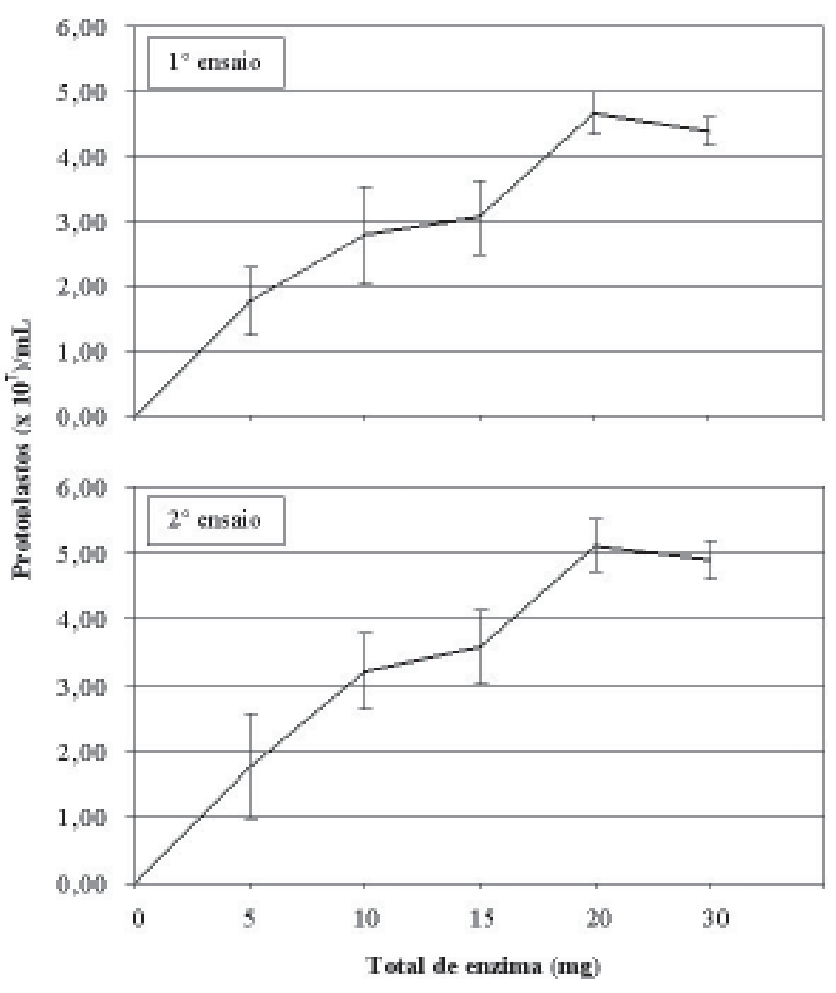

Figura 3. Número de protoplastos de Magnaporthe grisea, isolado I22, em função da concentração de Lysing Enzymes e Cellulase Onozuka R10. Mistura de digestão: $100 \mathrm{mg}$ de micélio, cada enzima variando de 2,5-15 mg e $3 \mathrm{~mL}$ de $\mathrm{MgSO}_{4} 1,2 \mathrm{M} / \mathrm{NaH}_{2} \mathrm{PO}_{4} 0,01 \mathrm{M}$, pH 5,8. Incubação sob agitação $(100 \mathrm{rpm})$ realizada por $5 \mathrm{~h}$ a $28-30^{\circ} \mathrm{C}$. As barras representam o desvio padrão.
Entre os sais, a solução à base de $\mathrm{NaCl}$ foi a menos eficiente na estabilização da protoplastização de I-22, possibilitando a produção de 1,3 e $0,9 \times 10^{7}$ protoplastos/ $\mathrm{mL}$ no primeiro e no segundo ensaio, respectivamente (Figura 4).

O uso de solução à base de sacarose ou sorbitol promoveu baixa produção de protoplastos, média dos ensaios de $0,6 \times 10^{7} / \mathrm{mL}$ e $0,9 \times 10^{6} / \mathrm{mL}$, respectivamente (Figura 4).

\section{Tempos de exposição ao sistema enzimático}

A protoplastização de $M$. grisea $\mathrm{I}-22$ foi monitorada a cada 60 min, durante 6 h de hidrólise enzimática. Nos dois ensaios, protoplastos do I-22 puderam ser observados com apenas $1 \mathrm{~h}$ de incubação, porém em baixo número (Figura 5). As maiores produções de protoplastos foram registradas com período de incubação de 3-6 h. Entre a terceira e quinta hora de incubação, o número de protoplastos manteve-se estável, em torno de 5,0 × 10\% $/ \mathrm{mL}$. A partir daí, observou-se redução na liberação de protoplastos em ambos os ensaios (Figura 5).

Está representada na Figura 6 uma preparação de protoplastos do isolado I-22 obtida com $3 \mathrm{~h}$ de incubação do micélio em estabilizador osmótico $\mathrm{MgSO}_{4} 1,2 \mathrm{M} /$ $\mathrm{NaH}_{2} \mathrm{PO}_{4} 0,01 \mathrm{M}, \mathrm{pH} 5,8$, contendo $10 \mathrm{mg}$ de Lysing Enzymes e $10 \mathrm{mg}$ de Cellulase Onozuka R10.

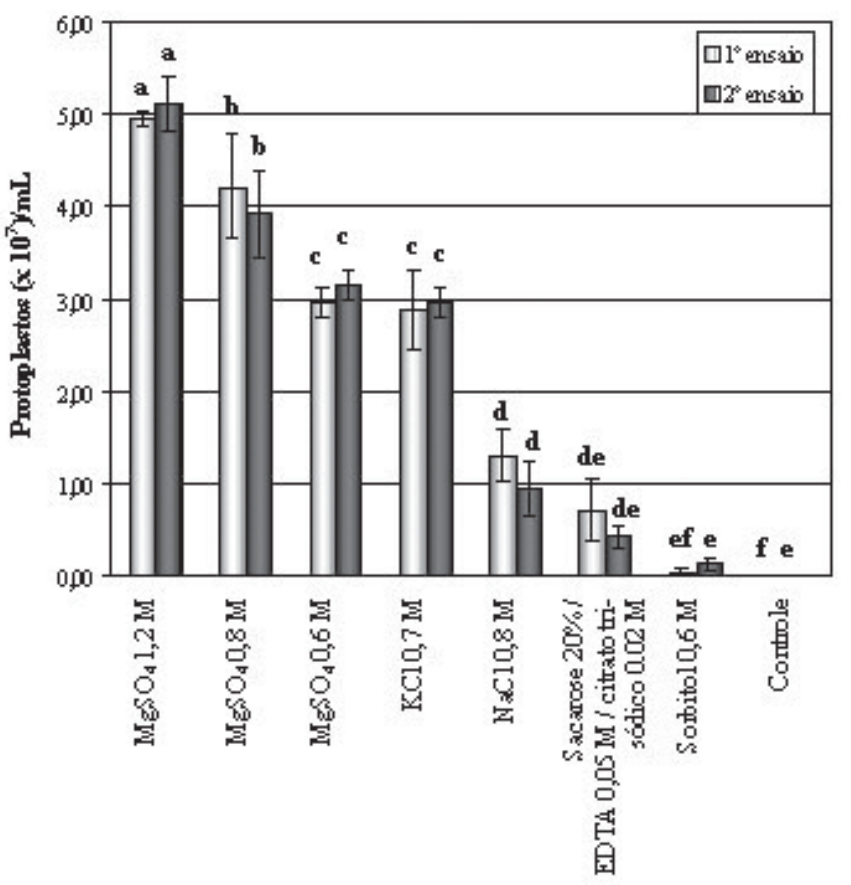

Figura 4. Número de protoplastos de Magnaporthe grisea, isolado I22, em função do estabilizador osmótico. Mistura de digestão: $100 \mathrm{mg}$ de micélio, $10 \mathrm{mg}$ de Lysing Enzymes, $10 \mathrm{mg}$ de Cellulase Onozuka $\mathrm{R} 10$ e $3 \mathrm{~mL}$ de estabilizador. Incubação sob agitação (100 rpm) realizada por $5 \mathrm{~h}$ a $28-30^{\circ} \mathrm{C}$. As barras representam o desvio padrão. Em cada ensaio, tratamentos com mesma letra não diferem entre si pelo teste de Tukey $5 \%$. 


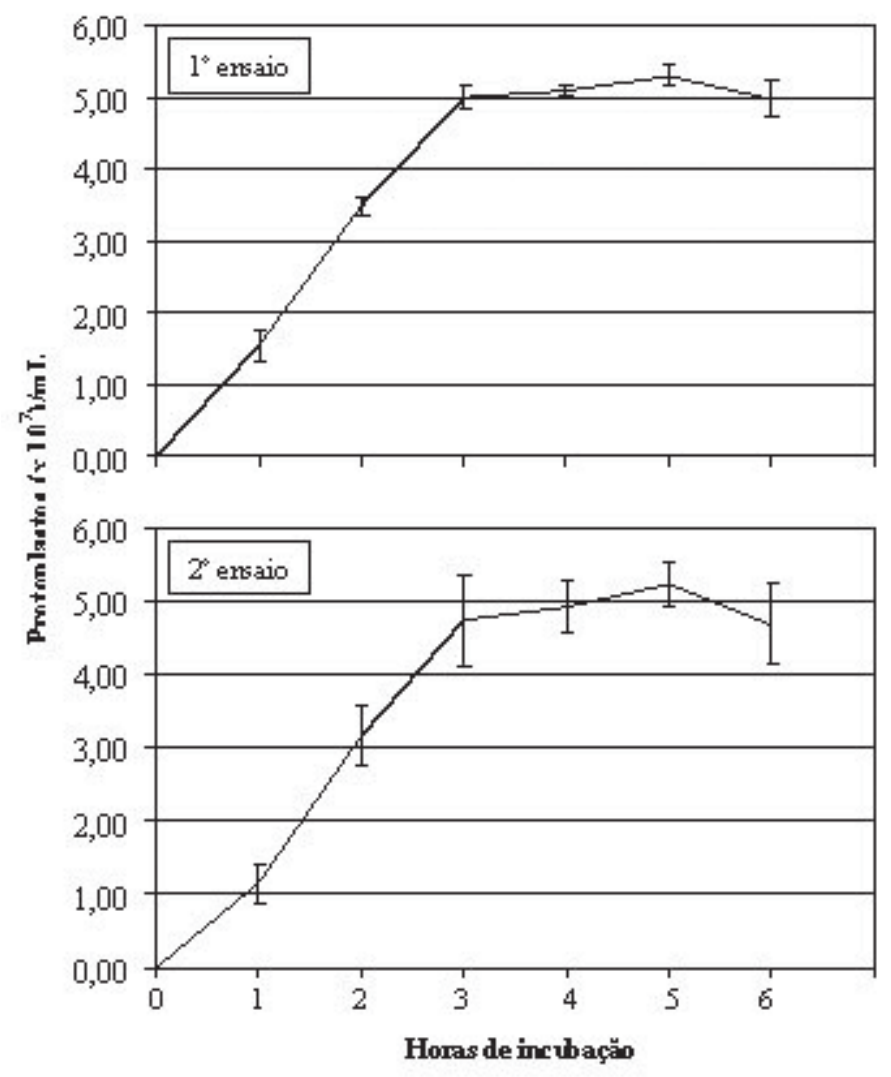

FIGURA 5. Número de protoplastos de Magnaporthe grisea, isolado I-22, em função do tempo de hidrólise enzimática. Mistura de digestão: $100 \mathrm{mg}$ de micélio, $10 \mathrm{mg}$ de Lysing Enzymes, $10 \mathrm{mg}$ de Cellulase Onozuka R10 e $3 \mathrm{~mL}$ de $\mathrm{MgSO}_{4}$ 1,2 M / NaH $\mathrm{PO}_{4} 0,01 \mathrm{M}$, pH 5,8. Incubação sob agitação $\quad(100 \mathrm{rpm})$ realizada a $28-30^{\circ} \mathrm{C}$. As barras representam o desvio padrão.

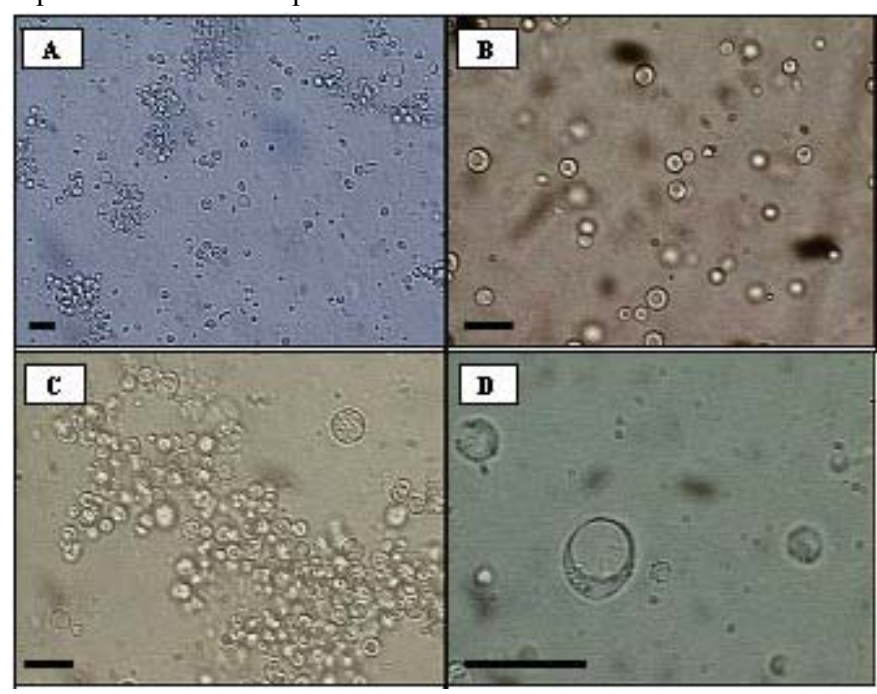

FIGURA 6. Fotomicrografias de protoplastos de Magnaporthe grisea, isolado I-22. A -Aumento de 200X. B e C - Aumento de 400X. D Aumento de 1000X. Mistura de digestão: $100 \mathrm{mg}$ de micélio, $10 \mathrm{mg}$ de Lysing Enzymes, $10 \mathrm{mg}$ de Cellulase Onozuka $\mathrm{R} 10$ e $3 \mathrm{~mL}$ de $\mathrm{MgSO}_{4}$ a $1,2 \mathrm{M} / \mathrm{NaH}_{2} \mathrm{PO}_{4} 0,01 \mathrm{M}, \mathrm{pH} 5,8$. Incubação sob agitação (100 rpm) realizada por $3 \mathrm{~h}$ a $28-30^{\circ} \mathrm{C}$. As barras na parte inferior das figuras correspondem a $10 \mu \mathrm{m}$.
Tabela 1. Porcentagem de regeneração de protoplastos de Magnaporthe grisea, isolado I-22, obtidos após 3, 4 ou 5 horas de hidrólise enzimática.

\begin{tabular}{ccccc}
\hline \multirow{2}{*}{$\begin{array}{c}\text { Tempo de Digestão } \\
\text { enzimática (h) }\end{array}$} & \multicolumn{4}{c}{ Regeneração (\%) } \\
\hline 3 & $\mathbf{1}^{\mathbf{0}}$ Ensaio & \multicolumn{2}{c}{$\mathbf{2}^{\mathbf{0}}$ Ensaio } \\
\hline 4 & $15,05^{\star *}$ & a & 19,42 & a \\
5 & 11,77 & b & 16,43 & b \\
& 7,95 & c & 9,13 & c \\
\hline
\end{tabular}

* Mistura de digestão: $100 \mathrm{mg}$ de micélio, $10 \mathrm{mg}$ de Lysing Enzymes, 10 mg de Cellulase Onozuka R10 e $3 \mathrm{~mL}$ de solução $\mathrm{MgSO}_{4}$ a $1,2 \mathrm{M} /$ $\mathrm{NaH}_{2} \mathrm{PO}_{4} 0,01 \mathrm{M}, \mathrm{pH} 5,8$. Incubação sob agitação $(100 \mathrm{rpm})$ realizada a $28-30^{\circ} \mathrm{C}$.

** Médias de 12 repetições. Valores seguidos pela mesma letra na coluna não diferem entre si pelo teste de Tukey $5 \%$.

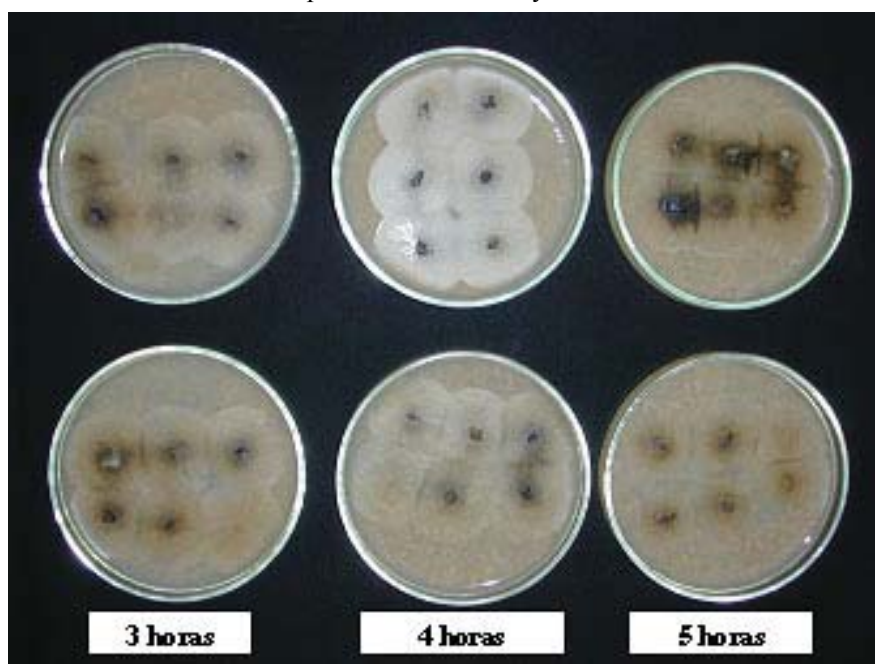

FIGURA 7. Crescimento micelial de Magnaporthe grisea, isolado I22, após a transferência das colônias do meio de regeneração (TB3) para o meio farinha de arroz-ágar (FAA). Avaliação realizada após 5 dias de incubação a $28^{\circ} \mathrm{C}$, no escuro. Os retângulos na parte inferior da figura indicam o tempo de hidrólise enzimática. Duas repetições de cada tratamento estão apresentadas.

\section{Regeneração dos protoplastos de $M$. grisea}

A regeneração dos protoplastos em TB3 foi relativamente rápida, com as primeiras colônias surgindo no terceiro ou quarto dia de incubação.

A freqüência de regeneração dos protoplastos do I-22 foi inversamente proporcional ao tempo de tratamento enzimático (Tabela 1). Maior porcentagem de regeneração foi obtida com protoplastos gerados com $3 \mathrm{~h}$ de hidrólise enzimática. Em ambos os ensaios, tempos maiores de exposição ao sistema enzimático resultaram em redução da capacidade regenerativa dos protoplastos.

Independentemente do tempo de hidrólise enzimática, constatouse crescimento micelial em todas as colônias que foram transferidas do meio TB3 para o FAA, com $24 \mathrm{~h}$ de incubação (Figura 7). A pigmentação das colônias iniciou-se após $72 \mathrm{~h}$ de cultivo, e com 120 $\mathrm{h}$ todas as colônias se apresentaram pigmentadas. 


\section{DISCUSSÃO}

Os ensaios para avaliar a influência dos sistemas líticos na protoplastização do isolado I-21 apresentaram variações consideráveis. Menores números de protoplastos foram obtidos no primeiro ensaio, o qual foi conduzido com micélio cultivado por $72 \mathrm{~h}$. No segundo ensaio usou-se micélio com $48 \mathrm{~h}$ de cultivo. Assim, acredita-se que o maior tempo de cultivo do micélio dificultou a liberação dos protoplastos, visto que alterações na parede celular, ocorridas durante o crescimento do fungo, poderiam conferir maior resistência à lise (19). Em geral, culturas fúngicas mais jovens tendem a liberar maior número de protoplastos $(9,11,23)$.

Embora Driselase tenha sido relatada como eficiente para a protoplastização de $M$. grisea $(3,28)$, este complexo enzimático não promoveu a liberação de protoplastos de I-21 e I-22. Características inerentes aos isolados, a fisiologia das culturas, aos lotes dos sistemas líticos (variação na proporção relativa das enzimas) e/ou à composição do estabilizador osmótico podem ter contribuído para os resultados divergentes.

A parede celular de $M$. grisea apresentou baixa sensibilidade a Cellulase Onozuka R10, o que convergiu com as observações de Asai et al. (3). Porém, ao ser utilizada simultaneamente com Lysing Enzymes ou Glucanex, a celulase promoveu aumentos expressivos na produção de protoplastos. Devido à complexidade e diversidade da parede celular das hifas, freqüentemente, a combinação de complexos enzimáticos resulta em maior eficiência na liberação de protoplastos de fungos filamentosos $(3,8,9,28)$. É acreditado que a atuação de um complexo enzimático torna o substrato do outro mais acessível, isto é, que ocorra ação sinergística entre os sistemas líticos (9).

A relação micélio:enzima mais adequada para protoplatizar o I-22 foi de 5:1, enquanto para o I-21 foi de 6,6:1 (dados não apresentados). Sistemas líticos mais concentrados levaram à atividade enzimática excessiva sobre os protoplastos, acarretando em rompimento da membrana plasmática e, conseqüentemente, menor número de protoplastos liberados.

Embora os estabilizadores osmóticos compostos por sorbitol ou sacarose sejam comumente utilizados na protoplastização de M. grisea $(5,14,25)$, observou-se que, para o isolado I-22, os estabilizadores salinos foram superiores àqueles. Efeito semelhante foi reportado para espécies de Fusarium (30) e Penicillium (6). Em geral, sais inorgânicos são mais eficientes na protoplastização de fungos filamentosos, enquanto açúcares ou açúcares-álcoois são mais apropriados para a liberação de protoplastos de leveduras (12). Por outro lado, o caráter mais ácido dos estabilizadores salinos pode ter favorecido a protoplastização do I-22, uma vez que o $\mathrm{pH}$ é fator crítico para a produção de protoplastos, por influenciar a atividade do complexo enzimático e do estabilizador osmótico (31).

Aparentemente, o tamanho dos protoplastos também foi influenciado pelo estabilizador osmótico utilizado. Protoplastos maiores foram observados quando sais foram usados para compor as soluções, o que pode ser devido à indução ou aumento de vacúolos nos protoplastos (17).

Com relação ao período de hidrólise enzimática do micélio, constatou-se que incubações prolongadas $(>5 \mathrm{~h}$ ) levaram a redução da eficiência de protoplastização, provavelmente devido à degeneração dos primeiros protoplastos liberados (11).

A maior porcentagem de regeneração dos protoplastos de $M$. grisea foi de $20 \%$, em contraste aos índices de $60-70 \%$ observados por Teraoka et al. (28). Desconsiderando-se as particularidades do isolado, alguns fatores podem ter comprometido a regeneração dos protoplastos de I-22. A temperatura do meio de regeneração, por exemplo, pode ter causado o rompimento dos protoplastos. Fato similar foi observado com Pisolithus tinctorius, sendo que o posterior plaqueamento dos protoplastos em meio solidificado, com temperaturas mais baixas, resultou no aumento da regeneração de $1,5 \%$ para $40 \%$ (2).

Adicionalmente, a presença de protoplastos anucleados pode ter influenciado na capacidade regenerativa dos protoplastos, conforme constatado para Crinipellis perniciosa, agente causal da vassoura-de-bruxa do cacaueiro, o qual apresentou $60 \%$ de protoplastos anucleados (13). Contudo, acredita-se que a freqüência de protoplastos anucleados em $M$. grisea seja relativamente pequena. Dos protoplastos do isolado P2 amostrados por Tanaka et al., apenas 9\% não apresentou núcleos (27).

Evidências sugerem que o sistema lítico utilizado para a protoplastização também afeta a capacidade regenerativa do protoplastos. Especificamente para $M$. grisea, constatou-se que os protoplastos liberados com Helicase (Pharmindustrie) não foram aptos a regenerar a parede celular (3). Assim, é possível que o complexo Lysing Enzymes-Cellulase Onozuka R10 tenha provocado danos na membrana plasmática que comprometeram a integridade dos protoplastos I-22. Segundo informação obtida por Vega (31), a presença de alta atividade proteolítica em Novozym 234 explicaria, em parte, as baixas freqüências de regeneração dos protoplastos algumas vezes obtidas com esse complexo enzimático.

O período de hidrólise enzimática foi outro fator que influenciou na capacidade regenerativa dos protoplastos. Aqueles protoplastos obtidos com incubação prolongada apresentaram menor capacidade de regeneração da parede celular. Talvez os resíduos de parede celular, presentes nos protoplastos liberados com menor tempo de hidrólise enzimática, facilitam a síntese da nova parede durante a regeneração (15). O sítio de origem dos protoplastos na hifa parental também poderia explicar a capacidade diferenciada de regeneração. Existe variabilidade quanto ao tamanho e presença de organelas (vacúolos e ribossomos, por exemplo) entre protoplastos liberados de regiões próximas e distais do ápice das hifas $(11,20)$, o que reflete em diferenças quanto ao potencial de regeneração (11). Assumindose que a parede celular na região apical das hifas, recentemente sintetizada, é mais prontamente degradada e que o potencial para a síntese da parede seja maior nessa região (11), foi esperada maior capacidade de regeneração dos protoplastos I-22 liberados com $3 \mathrm{~h}$ de hidrólise enzimática. Incubação adicional, provavelmente levou a protoplastização de regiões mais velhas da hifa, gerando preparação de protoplastos de qualidade inferior.

Os protoplastos de $M$. grisea apresentam diferentes padrões de regeneração (27). Normalmente, os protoplastos que seguem o padrão tipo 1, caracterizado pela formação de cadeias irregulares de células semelhantes às de leveduras, não regeneram completamente. Em determinado momento, sofrem autólise, sem reverterem à forma micelial normal. O ensaio de quantificação das colônias abortadas indicou que os protoplastos I-22 não exibiram o padrão de regeneração tipo 1 .

Alguns fatores importantes foram analisados para adequar as condições de isolamento e regeneração de protoplastos de $M$. 
grisea. O protocolo obtido poderá ser útil em programas de transformação e mutagênese REMI de $M$. grisea.

\section{REFERÊNCIASBIBLIOGRÁFICAS}

01.Aguilar, M.B.D. Atividade celulolítica e protoplastização em Humicola sp. e Trhichoderma pseudokoningii var. rifai. 1991. 112f. Tese (Doutorado em Genética e Melhoramento de Plantas) Escola Superior de Agricultura Luiz de Queiroz; Universidade de São Paulo, Piracicaba.

02.Anunciação, C.E. Obtenção e regeneração de protoplastos do fungo micorrízico Pisolithus tinctorius. 1989. 57f. Dissertação (Mestrado em Microbiologia Agrícola) - Universidade Federal de Viçosa, Viçosa.

03.Asai, T.; Okuno, T.; Matsuura, K. Isolation and germination type of protoplasts of spores and hyphae of Pyricularia oryzae. Annals of the Phytopathological Society of Japan, Tokyo, v.52, n.5, p.843849, 1986.

04.Balhadère, P.V.; Foster, A.J.; Talbot, N.J. Identification of pathogenicity mutants of the rice blast fungus Magnaporthe grisea by insertional mutagenesis. Molecular Plant-Microbe Interactions, St. Paul, v.12, n.2, p. 129-142, 1999.

05.Choi, W.; Dean, R.A. The adenylate cyclase gene MAC1 of Magnaporthe grisea controls appressorium formation and other aspects of growth and development. The Plant Cell, Rockville, v.9, n.11, p.1973-1983, 1997.

06.Dias, E.S.; Araújo, E.F.; Guimarães, W.V.; Coelho, J.L.C.; Silva, D.O. Production and regeneration of Penicillium expansum and Penicillium griseoroseum protoplasts. Revista de Microbiologia, São Paulo, v.28, n.2, p.116-120, 1997.

07.Fincham, J.R.S. Transformation in fungi. Microbiological Reviews, Washington, v.53, n.1, p.148-170, 1989.

08.Hamlyn, P.F.; Bradshaw, R.E.; Mellon, F.M.; Santiago, C.M.; Wilson, J.M.; Peberdy, J.F. Efficient protoplast isolation from fungi using commercial enzymes. Enzyme and Microbial Technology, Atlanta, v.3, n.4, p.321-325, 1981.

09.Hashiba, T.; Yamada, M. Formation and purification of protoplasts from Rhizoctonia solani. Phytopathology, St. Paul, v.72, n.7, p.849853, 1982.

10.Hosokawa, D.; Kozaka, T. Protoplasts isolation of Pyricularia oryzae. Annals of the Phytopathological Society of Japan, Tokyo, v.42, n.3, p.330, 1976. (Abstract 8).

11.Kim, B.K.; Kang, J.H.; Jin, M.; Kim, H.W.; Shim, M.J.; Choi, E.C. Mycelial protoplast isolation and regeneration of Lentinus lepideus. Life Sciences, Tucson, v.66, n.14, p. 1359-1367, 2000.

12.Lalithakumari, D. Protoplasts - a biotechnological tool for plant pathological studies. Indian Phytopathology, New Delhi, v.49, n.3, p.199-212, 1996.

13.Lima, J.O.; Santos, J.K. dos; Pereira, J.F.; Resende, M.L.V. de; Araújo, E.F. de; Queiroz, M.V. de. Development of a transformation system for Crinipellis perniciosa, the causal agent of witches' broom in cocoa plants. Current Genetics, Berlin, v.42, n.4, p.236-240, 2003.

14.Mitchell, T.K.; Dean, R.A. The cAMP-dependent protein kinase catalytic subunit is required for appressorium formation and pathogenesis by the rice blast pathogen Magnaporthe grisea. The Plant Cell, Rockville, v.7, n.11, p.1869-1878, 1995.

15.Necas, O. Cell wall synthesis in yeast protoplasts. Bacteriological Reviews, Washington, v.35, n.2, p.149-170, 1971.
16.Ou, S.H. Rice Diseases. 2.ed. Surrey: Commonwealth Mycological Institute. 1985. 380p.

17.Peberdy, J.F.; Gibson, R.K. Regeneration of Aspergillus nidulans protoplasts. Journal of General Microbiology, London, v.69, n.3, p.325-330, 1971.

18.Peberdy, J.F. Presidential address: fungi without coats - protoplasts as tools for mycological research. Mycological Research, Madri, v.93, n.1, p.1-20, 1989.

19.Peberdy, J.F.; Buckley, C.E.; Daltrey, D.C.; Moore, P.M. Factors affecting protoplast release in some filamentous fungi. Transactions of the British Mycological Society, London, v.67, n.1, p.23-26, 1976.

20.Queiroz, M.V. de. O efeito da protoplastização na instabilidade mitótica de Aspergillus nidulans. 1988. 136f. Dissertação (Mestrado em Genética e Melhoramento de Plantas) - Escola Superior de Agricultura Luiz de Queiroz; Universidade de São Paulo, Piracicaba.

21.Ruiz-Díez, B. Strategies for the transformation of filamentous fungi. Journal of Applied Microbiology, Oxford, v.92, n.2, p.189-195, 2002.

22.Schiestl, R.H.; Petes, T.D. Integration of DNA fragments by illegitimate recombination in Saccharomyces cerevisiae. Proceedings of the National Academy of Sciences of the United States of America, Washington, v.88, n.17, p.7585-7589, 1991.

23.Shabana, Y.M.; Charudattan, R. Preparation and regeneration of mycelial protoplasts of Alternaria eichhorniae. Journal of Phytopathology, Berlin, v.145, n.7, p.335-338, 1997.

24.Shi, Z.; Christian, D.; Leung, H. Enhanced transformation in Magnaporthe grisea by restriction enzyme mediated integration of plasmid DNA. Phytopathology, St. Paul, v.85, n.3, p.329-333, 1995.

25.Sweigard, J.A.; Carroll, A.M.; Farrall, L.; Chumley, F.G.; Valent, B. Magnaporthe grisea pathogenicity genes obtained through insertional mutagenesis. Molecular Plant-Microbe Interactions, St. Paul, v.11, n.5, p.404-412, 1998.

26.Talbot, N.J.; Ebbole, D.J.; Hamer, J.E. Identification and characterization of $M P G 1$, a gene involved in pathogenicity from the rice blast fungus Magnaporthe grisea. The Plant Cell, Rockville, v.11, n.5, p.1575-1590, 1993.

27.Tanaka, H.; Ogasawara, N.; Kamimiya, S. Protoplasts of Pyricularia oryzae $\mathrm{P} 2$ : preparation and regeneration into hyphal form. Agricultural and Biological Chemistry, Tokyo, v.45, n.7, p. 15411552,1981

28.Teraoka, T.; Shimura, Y.; Hosokawa, D.; Watanabe, M. Giant protoplasts of Pyricularia oryzae Cavara. Annals of the Phytopathological Society of Japan, Tokyo, v.58, n.5, p.726733, 1992.

29.Valent, B.; Farrall, L.; Chumley, F.G. Magnaporthe grisea genes for pathogenicity and virulence identified through a series of backcrosses. Genetics, Pittsburgh, v.127, n.1, p.87-101, 1991.

30.Vazquez, F.; Figueroa, L.I.C. de. Protoplasts formation in Fusarium species. Biotechnology Techniques, London, v.10, n.2, p.93-98, 1996.

31.Vega, M.E. Aspectos genéticos da parameiose via fusão de protoplastos em Metarhizium anisopliae (Metsch.) Sorokin. 1990. 95f. Dissertação (Mestrado em Genética e Melhoramento de Plantas) - Escola Superior de Agricultura Luiz de Queiroz; Universidade de São Paulo, Piracicaba. 
O arquivo disponível sofreu correções conforme ERRATA publicada no Volume 32 Número 4 da revista. 